\title{
Violência de gênero entre gamers brasileiros: um estudo exploratório no Facebook ${ }^{1}$
}

\author{
Suely Fragoso ${ }^{2}$ \\ Raquel Recuero3 \\ Mayara Caetano 4
}

\begin{abstract}
Resumo:Apresentamos neste texto os resultados de um estudo exploratório voltado à identificação de registros de ocorrências de violência contra a mulher em páginas do Facebook dedicadas a games, especialmente aquelas voltadas para denúncias de violência, violência de gênero e temas correlatos. Ao contrário do que era esperado, não encontramos evidências dessas práticas ou discursos em quantidade ou com regularidade suficiente nos posts nem nos comentários publicados nessas páginas. Analisamos a página onde as menções a violência de gênero eram mais frequentes segundo uma abordagem mista, combinando métricas de análise de redes e análise de contingência. Essa análise confirmou que o número de posts sobre questões de gênero era baixo, mas indicou a) que as questões de gênero são objeto de atenção, b) que há diferenças no vocabulário utilizado para fazer referência a jogadores e jogadoras e c) a ocorrência de agressões às mulheres durante o jogo. Esses resultados são compatíveis com três cenários, nos quais: a) as jogadoras podem não se dar conta das situações de violência de gênero; b) as jogadoras percebem as agressões, mas preferem não publicar sobre elas; c) as publicações acontecem, mas são apagadas pelos moderadores das páginas ou grupos, por motivos diversos. Em qualquer caso, a ausência de registros de violência de gênero entre jogadores brasileiros dificulta os estudos sobre o tema e abre o caminho para a negação de sua existência por interpretações interessadas ou pouco cautelosas.
\end{abstract}

1 Trabalho apoiado pelo Conselho Nacional de Desenvolvimento Científico e Tecnológico - CNPq - Brasil.

${ }^{2}$ Professora Titular da Universidade Federal do Rio Grande do Sul (UFRGS), onde atua nos cursos de Pós-Graduação em Comunicação e Informação (PPGCom) e em Design (PGDesign) e no Curso de Graduação em Comunicação Social.E-mail: suelyfragoso@ufrgs.br

3Professora e pesquisadora do Centro de Letras e Comunicação da Universidade Federal de Pelotas e pesquisadora do Programa de Pós-Graduação em Comunicação da Universidade Federal do Rio Grande do Sul (UFRGS). Pesquisadora do CNPq. Email: raquel@raquelrecuero.com

4 Mestranda do Programa de Pós-Graduação em Comunicação e Informação da Universidade Federal do Rio Grande do Sul.E-mail: mayarcae@gmail.com 
Palavras-chave:gênero; violência; games; Facebook; análise de contingência.

\begin{abstract}
In this text we present the results of an exploratory study which aimed at the identification of registries of violence against women in Facebook pages dedicated to games, especially those aimed at denouncing violence, gender violence and related issues. Contrarily to our expectations, we did not find evidence of such practices or discourses in quantity or with sufficient regularity in the posts or comments published on these pages. We analysed the page where the mentions of gender violence were more frequent using a mixed approach which combined metrics of network analysis and contingency analysis. This confirmed that the number posts about gender issues was small, but indicated a) that gender issues receive attention, b) the presence of differences in the vocabulary used to refer to male and female players and c) the occurrence of aggressive in-game attitudes towards female players. These results are compatible with three scenarios, in which a) players may not be aware of the situations of gender violence; b) players perceive the aggressions, but prefer not to publish on them; c) the publications occur, but are deleted by the moderators of the pages or groups, for different reasons. In any case, the absence of records of gender violence among Brazilian players makes it difficult to study the subject and opens the way to the denial of the existence of such practices and discourses in interested or inattentive interpretations.
\end{abstract}

Keywords:gender; violence; games; Facebook; contingency analysis.

Por um longo tempo, as problematizações dos usos e apropriações das tecnologias digitais nas Ciências Humanas e Sociais em geral e, em especial, na Comunicação foram polarizadas por enfoques que, embora opostos em suas conclusões, compartilhavam a mesma premissa: a da separação entre os âmbitos real e virtual, online e offline, digital e material. Tanto as visões eufóricas quanto os anúncios de um futuro desolador foram marcados pela persistência dessa dualidade, cuja atratividade é compreensível. Por um lado, os debates mobilizados por polarizações que compartilham as mesmas crenças de base são mais fáceis e prazerosos do que aqueles em que essas crenças são postas em dúvida. Por outro, esse modo de pensar baseado na separação entre corpo e espírito, mente e matéria, espaço físico e território simbólico converge com linhas milenares de conhecimento e crença da cultura ocidental e contam também com amplo apoio do senso comum.

Denúncias da presença dessa tendência e da necessidade de superá-la (cf. WERTHEIM, 1999; FRAGOSO, 2008, 2010; FELINTO, 2005) abriram caminho 
para abordagens em que o offline e o online deixaram de ser considerados como esferas independentes. Fatores que pareciam externos à internet e à comunicação mediada por ela, bem como entre os conteúdos e as formas das interações sociais online para âmbitos da vida que, à primeira vista, aparentam ser dissociados da rede, passaram a ser vistos de forma integrada. Um desses casos é a violência presente em diversos segmentos da Internet e sob diferentes matizes, como a violência simbólica de gênero, que se tornou mais relevante nas problematizações acadêmicas (ACCIOLY, 2016; RECUERO, 2014; SOARES, 2016a, 2016b; LINS, 2016; FREDA, 2014). Essa visão constitui um dos pressupostos fundamentais deste artigo, cuja proposta é analisar a violência simbólica nos games, tomando como base empírica páginas dedicadas a jogos no Facebook.

A relação com a violência tem sido objeto de atenção desde os primeiros anos dos videogames. Trabalhos brasileiros voltados para o tema problematizam questões como a indução a comportamentos violentos (cf. ALVES, 2005; RIBEIRO et al., 2011) e, sobretudo mais recentemente, a violência de gênero nos próprios games ou nos ambientes de game (cf. OLEGÁRIO et al., 2009; FONSECA, 2013; OLIVEIRA, 2014).

Discutiremos neste texto a violência simbólica contra a mulher em ambientes relacionados a games, questionando a quantidade e a regularidade de manifestações desse tipo. A título de contextualização, iniciaremos com considerações sobre a violência em geral e prosseguiremos para a violência na internet e violência de gênero em ambientes online. Em seguida, trataremos da violência em games. De posse do arcabouço teórico assim constituído, apresentaremos a proposta metodológica, os resultados obtidos com sua aplicação e a análise dos mesmos.

\section{Discurso, violência e gênero na internet}

A violência pode assumir várias formas. Zizek (2008), por exemplo, aponta três tipos de violência, interligados. A violência subjetiva seria a parte "mais visível" do espectro, por exemplo, atos terroristas, brigas, ou seja, expressões agudas facilmente identificáveis. Os dois outros tipos de violência 
são mais sutis. A violência objetiva, que Zizek chama também de violência simbólica, está associada à linguagem, ao discurso e aos sentidos construídos pela sociedade. Já a violência sistêmica está associada aos sistemas econômicos e políticos e a seus efeitos.

O conceito de violência simbólica é também utilizado por Bourdieu (1991), que compreende o discurso como uma forma de legitimação da dominação econômica e simbólica na sociedade. Para o autor, a violência simbólica advém não apenas da linguagem, mas da naturalização das relações de poder, da imposição de uma determinada ordem social. Bourdieu também associa essa violência ao discurso, cuja função é aquela de constituir o poder simbólico.

Assim, embora Zizek e Bourdieu utilizem a denominação violência simbólica para designar manifestações ligeiramente diferentes, o discurso é, para ambos, um instrumento que está inserido no sistema da violência, contribuindo para a justificativa e a própria violência física. É interessante notar também que a violência discursiva não acontece apenas ou necessariamente em discursos de ódio ou sobre o ódio. Ela pode estar nas expressões cotidianas, "naturalizadas" por um determinado grupo, que constituem um conjunto de ideias que está presente na sociedade e que terminam por legitimar ideias que ofendem ao outro. Por exemplo, se alguém critica a forma de um garoto jogar videogame dizendo que ele joga "como uma garota", a intenção é claramente derrogatória, implicando no "fato" de que garotas não são capazes de jogar bem. Assim, a qualificação de que um menino, ou um homem, assim, possa fazer algo "como mulher" é implicada como ruim e ofensiva. Obviamente, tal expressão constitui também a visão social do que é uma mulher.

\section{O Discurso e a Violência Simbólica no Brasil}

Herring (2003, p.12) argumenta que "o discurso da Internet 'herda' as assimetrias das estruturas econômicas e sociais vigentes", ou seja, traduz também ideias presentes na sociedade, não constituindo uma esfera diferente daquela. Em outras palavras, os discursos na rede reproduzem as estruturas de 
dominação da sociedade onde estão inseridos e são uma expressão das relações de poder que estão intrínsecas à sociedade.

As preocupações com o papel da internet na reprodução da violência simbólica não refletem uma preocupação recente. Entre os exemplos relativos ao Brasil vemos, por exemplo, a "tomada do Orkut" pelos brasileiros (FRAGOSO, 2006), relacionada a manifestações xenófobas e de ódio notadamente em comunidades como "Eu odeio os Estados Unidos" e "Why do you hate Brazilians". Enquanto a imprensa e certa parte do mundo acadêmico (cf. ALERIGI, 2004; LEITE, 2005) insistiam em explicar o enorme sucesso do Orkut no Brasil conforme o mito do brasileiro pacífico e amigável (HOLLANDA, 1995)5, as interações no próprio Orkut apontavam um discurso claramente agressivo, mas que também desvela estruturas de poder simbólico e da própria compreensão sobre o Brasil pelos brasileiros e estrangeiros, especialmente estadunidenses (FRAGOSO; HACKNER, 2017).

Outros trabalhos trouxeram questões diferentes. Por exemplo, Recuero (2014) demonstrou como as ausências de determinadas palavras e conceitos nos tweets sobre o Dia da Consciência Negra desvelavam associações da data unicamente com o feriado e muito pouco com a luta do povo negro. Ou seja, o negro deixava de ser protagonista da data, que teve sua significação revertida e passou a reproduzir a estruturação social vigente, na contramão da necessidade de conscientização que a motiva.

Recuero, Zago e Bastos (2014) e Recuero (2014) registraram e discutiram exemplos de violência simbólica em sites de redes sociais no contexto dos processos eleitorais, tanto em escala regional, quanto federal, atingindo eleitores e candidatos com insultos e ameaças atingindo tanto candidatos quanto eleitores. Os discursos agressivos identificados pelos autores apontam a ruptura da sociedade brasileira, cujos posicionamentos políticos encontram-se dicotomizados.

5 Essa ideia seria uma interpretação romantizada do "brasileiro cordial", chave interpretativa que Sérgio Buarque de Hollanda (1995) recupera justamente para contestar. Para outras considerações sobre esse ponto, cf. Fragoso, 2006, 2014;Fragoso; Hackner, 2014. 
$\mathrm{Na}$ disputa eleitoral presidencial de 2010 havia duas candidatas do gênero feminino disputando o cargo e um homem. De acordo com a análise do Horário Público de Propaganda Eleitora, programa obrigatório na grade aberta de televisão durante o período de eleições, e da cobertura jornalística do Jornal Nacional, da Rede Globo, as autoras Mota e Biroli (2014) observaram que, nos dois programas, atributos convencionais sobre mulheres foram reiterados, como a relação com a maternidade, e, consequentemente, questões como direitos reprodutivos femininos foram evitados nas discussões políticas, pois pautas centradas em mulheres estão sub-representadas, assim como a sua participação dos quadros de representação nacional.

Em um cenário intolerante e polarizado, a radicalização política convergiu com a violência de gênero tendo como foco a própria presidenta da República. Na análise da representação e da significação da imagem pública da presidenta, durante seu segundo mandato, em revistas semanais de grande tiragem, as autoras Boroski e de Carvalho (2016) encontram no discurso desses veículos a relação entre má gestão e denúncias de corrupção como consequências da identidade de gênero da líder política. Complementando essa cobertura midiática negativa, Stocker e Dalmaso (2016) mapearam os comentários no Facebook em publicações da Folha de S. Paulo após um dos protestos pró-impeachment. As autoras constataram que $56 \%$ dos comentários eram relacionados a questões de gênero e continham ódio e misoginia, por exemplo.

\section{Games, Violência Simbólica e Gênero}

As questões de gênero estão entre as de maior destaque nas discussões sobre violência e discurso em games. Em jogos offline, por exemplo, a literatura aponta tanto as reservas de protagonismo aos personagens masculinos (PROVENZO, 1991), quanto as formas de representação do feminino na figura de personagens infantilizadas ou hipersexualizadas que ocupam o lugar de prêmios e recompensas (IVORY, 2006, DILL; THILL, 2007; FISCHER, 2015). Registros e denúncias desse tipo de representação aparecem desde os primeiros estudos sobre games, como indica o levantamento bibliográfico realizado por 
Friman (2015). Um exemplo extremo foi registrado por Provenzo (1991), que descreveu o caso de um jogo dos anos 1980, Custer's Revenge, em que a violência de gênero convergia com o racismo. "Jogadores que conseguiam atravessar cactos espinhosos e chuvas de flechas podiam assistir a um oficial assaltar sexualmente uma mulher indígena indefesa, porém sorridente, que estava amarrada a uma estaca6" (PROVENZO, 1991, p.52, tradução nossa).

Para Fragoso(1998), a interatividade dos games eleva a violência simbólica a um novo patamar, pois o impacto da agência no efeito de realidade é mais forte que o do realismo gráfico. Esse fator é intensificado nos jogos online, nos quais as interações acontecem entre jogadores. Um dos exemplos mais antigos de violência simbólica que tirou partido das possibilidades da interatividade e interação social em ambientes mediados pela internet foi o ataque virtual protagonizado por um avatar identificado como $\mathrm{Mr}$ Bungle na LambdaMOO7. O acontecimento tornou-se mais conhecido na versão da narrativa de Dibbel, publicada em 1993 no periódico alternativo The Village Voice. Para as finalidades do presente texto, não é necessário reproduzir a riqueza de detalhes do texto de Dibbell, sendo suficiente assinalar o destaque dado pelo autor aos efeitos traumáticos daquele "estupro no ciberespaço" (DIBBEL, 1998) sobre as mulheres atacadas ${ }^{8}$.

Mais recentemente, dois eventos de violência de gênero nos jogos online tiveram grande repercussão: a reação ao projeto intitulado "Tropes vs Women in Video Games", em 2012, e o Gamergate, em 2014. No primeiro caso, a visibilidade alcançada pela proposta de realização de uma série de vídeos sobre padrões de representação de mulheres nos games apresentada na plataforma de

\footnotetext{
6"Players who were able to get through thorny cactus and a hail of arrows got to watch an officer sexually assault a helpless but smiling Indian woman tied to a stake"

7 A LambdaMOO foi um dos mais populosos ambientes virtuais baseados em texto nos anos 1990. MOOs são um tipo especial de MUD (Multi-User Dungeons or Domains), sistemas de realidade virtual baseados em texto.

8 Embora a literatura do período enfatizasse o espírito colaborativo das comunidades virtuais (RHEINGOLD, 1996), a narrativa de Dibbell (1993) não se exime de mencionar que a punição a Mr Bungle foi igualmente violenta.
} 
arrecadação Kickstarter ${ }^{9}$ chamou a atenção tanto de apoiadores quanto de haters, cujos insultos à mentora do projeto transformaram-se em ameaças de outros tipos de violência, inclusive estupro e morte. Já o Gamergate iniciou quando uma desenvolvedora de jogos foi acusada de envolver-se com um jornalista para conseguir uma boa avalição de seu jogo. Sob olhares difamatórios, a desenvolvedora tentou defender-se enquanto aumentava o número de pessoas dispostas a apoiá-la ou a agredi-la. As ações coordenadas por seus agressores foram coordenadas e divulgadas pelo Twitter com a hashtag \#gamergate, nome pelo qual a controvérsia tornou-se conhecida (JOHNSTON, 2014).

No Brasil, os trabalhos acadêmicos sobre a agressão em games têm resultados diferentes dos estadunidenses, apontando a importância das balizas culturais para a percepção da violência simbólica. Olegário et al. (2009) diagnosticaram um impedimento simbólico das mulheres por parte de frequentadores de lan houses ${ }^{10}$. Dentre aspoucas mulheres, predominavam as que haviam começado a frequentar aqueles ambientes como acompanhantes de namorados ou amigos homens. Como contraponto a esse papel coadjuvante, os autores buscaram as garotas que jogavam em clãs. Os resultados confirmaram o predomínio de estereótipos, porém com poucas referências a violência ou mesmo a preconceitos de gênero.

As jogadoras brasileiras entrevistadas por Fortim e Grando (2014) preferiam jogar com avatares femininos e utilizar nomes igualmente femininos, mas apenas $3 \%$ relataram terem sido alvo de violência de gênero. Nota-se, no entanto, que a maioria das jogadoras brasileiras entrevistadas não consideravam abusivo o flerte, nem mesmo o chamado "machismo benevolente", que consiste em proteger e dar presentes às jogadoras devido ao seu gênero (YEE, 2008).No entanto, como destacam as autoras, em pelo menos um relato ficou claro que a recusa desse protecionismo deu margem a

9Disponível em: <https://www.kickstarter.com/projects/566429325/tropes-vswomen-in-video-games $>$. Acesso em: 13 abr. 2017.

${ }^{10}$ Lan houses são espaços comerciais com vários computadores disponíveis para acesso à internet, com custo por tempo de uso. 
tratamento agressivo (FORTIM; GRANDO, 2014). Por outro lado, as jogadoras brasileiras consideravam agressivo que os outros jogadores não acreditassem que elas eram mulheres.

Outros trabalhos brasileiros convergem com essa percepção, ao indicarem que as jogadoras reiteram que existe violência de gênero nos games, mas os exemplos são poucos. Fonseca (2013) realizou entrevistas que apontaram que a reação das mulheres brasileiras à caracterização hipersexualizada das personagens nos games não é negativa, embora considerem preferíveis qualidades como determinação e coragem, com as quais se identificam. Já Oliveira (2014) estudou as trocas conversacionais em uma página no Facebook intitulada "Garotas que jogam Videogame". Os dados do autor indicam que as mulheres interagem pouco nesta página e, por vezes, reforçam os estereótipos de gênero. Além disso, a moderação da página publica e divulga conteúdos que reproduzem padrões sexistas, sob alegação de humor.

Em síntese, a literatura científica indica um quadro peculiar, com poucos exemplos concretos de violência de gênero em games no Brasil, situação que se complexifica diante da percepção difusa do que constitui esse tipo de violência por parte das jogadoras. Neste cenário, o estudo que apresentamos a seguir questiona a quantidade e a regularidade de expressões de violência contra a mulher em ambientes relacionados a games.

\section{Abordagem metodológica}

Nesta seção, apontamos a escolha dos ambientes onde o estudo foi realizado e descrevemos os métodos de coleta e análise dos dados.

A dificuldade de estudar a violência de gênero nos próprios jogos online começam nas características dos próprios ambientes de jogo. As interações nos games acontecem em vários servidores ao mesmo tempo e em tempo real, o que dificulta os registros. Emestudos anteriores sobre práticas disruptivas de jogadores brasileiros (FRAGOSO, 2015; FRAGOSO; HACKNER, 2017), dois auxiliares de pesquisa participaram dos jogos League of Legends e Dota2 durante duas semanas, mantendo ligados os equipamentos de gravação, mas não tiveram oportunidade de registrar episódios de violência de qualquer tipo. 
Algumas semanas após o término dessa experiência, em um intervalo de poucas horas, uma pesquisadora testemunhou duas situações de violência simbólica em League of Legends, sem que houvesse tempo de acionar os sistemas de registro. Devido a essas dificuldades, nossa busca de registros de violência de gênero foi direcionada para outros ambientes, especialmente grupos e páginas dedicados a games no Facebook.

Para analisar os discursos encontrados nessas páginas, utilizamos um conjunto de métodos e técnicas quantitativas e qualitativas: uma abordagem mista composta de análise de contingência (RECUERO; BASTOS; ZAGO, 2015) e métricas de análise de redes (WASSERMAN; FAUST, 1994). A análise de contingência é um braço da análise de conteúdo em que os termos são classificados em conceitos de acordo com o sentido construído, buscando fazer vários níveis de classificações até chegar em categorias abrangentes. Neste trabalho, buscamos classificar os termos mais utilizados pelos atores em conceitos de acordo com os objetivos da pesquisa (por exemplo, focamos em substantivos e adjetivos). Após, a análise de contingência analisa as coocorrências entre esses conceitos e suas relações. Neste trabalho, este é o momento onde observamos a interconexão entre os conceitos, analisando as relações entre eles e sua frequência em cada unidade (um comentário no Facebook). Para compreender a estrutura dessas associações, utilizamos métricas de análise de redes que também permitiram a construção de representações visuais dessas relações através de grafos. Dentre essas métricas consideradas, destacamos: a) grau; b) peso da aresta e c) modularidade. O grau é dado pela quantidade de conexões que um determinado nó recebe ou faz na rede. Em nosso caso, os nós são os conceitos observados e as conexões, o número de vezes que o conceito aparece em relação aos demais. Assim, o tamanho do conceito no grafo indica sua presença nos dados. Quanto maior, mais presente esteve nas várias relações mostradas pelo grafo. $O$ peso da aresta é dado pela quantidade de conexões entre dois nós. Assim, quanto maior a quantidade de vezes onde a associação apareceu nas unidades de análise (comentários), mais forte é a conexão. Deste modo, quanto mais grossa a conexão entre dois conceitos específicos, mais frequente estes foram observados 
na mesma unidade. A modularidade é uma medida de grupabilidade, que mostra quais conjuntos de nós (conceitos) tendem a estar mais próximos, ou seja, a aparecer citados em conjunto com maior frequência. A modularidade, nos grafos, é representada pelas cores. Cores iguais mostram conceitos que tendem a aparecer no mesmo grupo. Trazemos na análise os dados gerais e os dados normalizados. A normalização permite retirar o peso da repetição de comentários (spam), por exemplo, auxiliando a enxergar um conjunto mais amplo de associações construídas pelos atores, de modo que possamos perceber como são representadas as mulheres nestes dados.

\section{Descrição dos Procedimentos}

Inicialmente, identificamos 10 (dez) ${ }^{11}$ páginas e grupos do Facebook cujas propostas tornavam mais provável a ocorrência de registros a respeito de violência de gênero em games e observamos as publicações em cada uma delas durante 6 meses (julho a dezembro de 2015). Apesar do direcionamento temático inicial, não encontramos material em quantidade nem com continuidade suficiente para comprovar a importância desse fenômeno naqueles ambientes. Isso se aplica mesmo àquelas especialmente dedicadas a

${ }^{11}$ As páginas acompanhadas foram:

League of Legends - DenúnciaDisponível em:<https://www.facebook.com/loldenuncia/> . Acesso em: 13 abr. 2017.

Counter Strike Global Offensive -Disponível em:<https://www.facebook.com/OfficialCStrike/> . Acesso em: 13 abr. 2017.

League of Jungle - Disponível em:<https://www.facebook.com/Leagueofjungle/ $>$. Acesso em: 13 abr. 2017.

CS da Depressão - Disponível em:<https://www.facebook.com/CSDDP $>$. Acesso em: 13 abr. 2017.

$\begin{array}{lllll}\text { Machistas do } & \text { Mundo } & & \text { Deek isponível }\end{array}$ em:<https://www.facebook.com/machistasdomundogeek>. Acesso em: 13 abr. 2017.

Gamer, você é machista - e Disponível em: <https://www.facebook.com/gamermachista >. Acesso em: 13 abr. 2017.

Indiretas de League of Legends - Disponível em:<https://www.facebook.com/IndiretasdoLoL>. Acesso em: 13 abr. 2017.

Jogue como uma Mulher - Disponível em:<https://www.facebook.com/groups/439112316287433>. Acesso em: 13 abr. 2017.

Gamer Não Tem Gênero - Disponível
em: <https://www.facebook.com/gamerntgenero/> . Acesso em: 13 abr. 2017.

League of Sexism - Disponível em:<https://www.facebook.com/LeagueOfSexism/ >. Acesso em: 13 abr. 2017.

UOL jogos- Disponível em:<https://www.facebook.com/UOLJogos $>$. Acesso em: 13 abr. 2017. 
denúncias sobre agressões, como League of Legends - Denúncia ${ }^{12}$, declaradamente "criada por jogadores para unir as minorias oprimidas in game contra misoginia, racismo, homofobia e transfobia”. Na data da última observação, essa página contava com apenas 14 posts visíveis.

A página com maior quantidade de posts e comentários durante aquele primeiro período de observação foi a League of Jungle, também relacionada ao game League of Legends. Escolhemos um período de 15 dias para uma análise quantitativa com postagens dessa página, correspondente à primeira quinzena de outubro de 2015. A coleta resultou em 235 postagens, que observamos individualmente, para verificação temática. Apenas 4 deles endereçavam questões de gênero. A seguir, incorporamos à amostra os 26.332 comentários e submetemos o total aos procedimentos de análise anteriormente descritos.

Diante dessa baixa quantidade, ampliamos a coleta para todos os posts e comentários da página League of Jungle durante o ano de 2015. As 419.711 postagens recolhidas foram submetidas aos mesmos procedimentos anteriores. Nesse conjunto, identificamos os que se referiam a mulher(es), menina (s), garota(s) etc., que representaram uma parcela muito baixa (2.046 postagens, pouco menos de $5 \%$ ), com os quais construímos os mapas que apóiam a discussão a seguir.

Na próxima seção, discutimos os resultados encontrados na coleta de posts e comentários do ano de 2015.

\section{Análise}

A pequena proporção de posts e comentários com as palavras-chave utilizadas para a localização de conteúdo relacionado a gênero indica que a maior parte das discussões na página ou não passa pelas questões de gênero, ou que posts e comentários sobre o assunto são ocultados ou apagados. Por outro lado, embora em menor quantidade, existem registros com as palavras-chave, $o$ que indica que o tema aparece em algumas threads. As Figuras 1 e 2 mostram,

12 "Página criada por jogadores para unir as minorias oprimidas in game contra misoginia, racismo, homofobia e transfobia" (Acesso em: out 2016). 
respectivamente, os mapas geral e normalizado dos posts e comentários na página League of Jungle em 2015 que continham as palavras-chave.

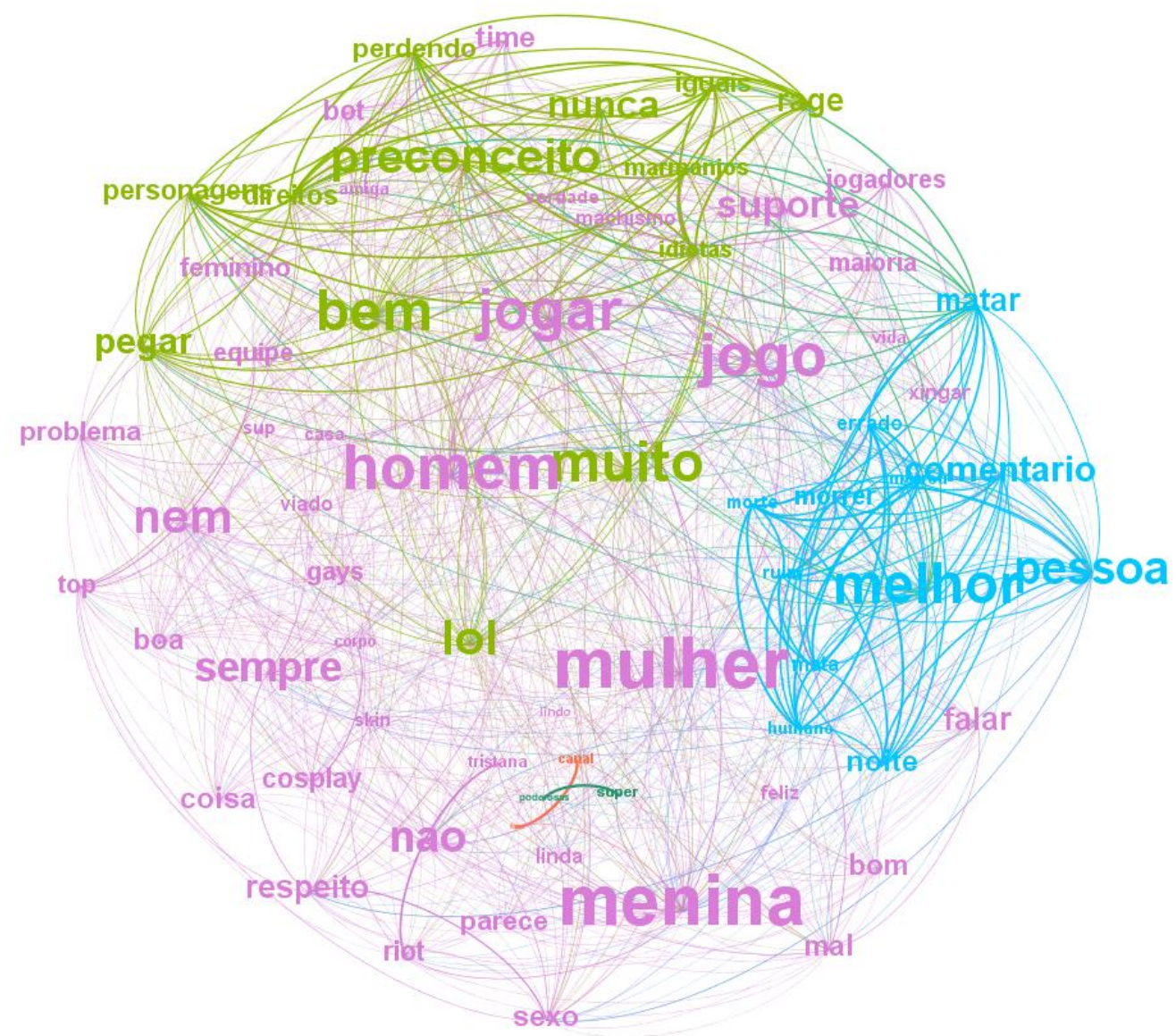

Figura 1: mapa dos posts e comentários que continham as palavras-chave mulher(es), menina (s), garota(s) e afins, na página League of Jungle no ano de 2015.

No mapa, vemos três grandes grupos. O conjunto em verde traz conceitos relacionados a "preconceito", por exemplo. É interessante observar que não estão neste grupo os conceitos de "mulher" e "menina", o que indica distância do tema associado ao debate sobre "preconceito" e "marmanjos". O grupo azul traz conceitos relacionados a elogios aos jogadores. E o grupo rosa traz os conceitos mais centrais a este trabalho, "mulher", "menina" e "homem".

Notamos aqui um exemplo de violência discursiva naturalizada no vocabulário cotidiano, ou seja, uso de expressões que, embora sejam consideradas "normais", demarcam a superioridade de um grupo sobre outro (BOURDIEU, 1991). Em nossos resultados, isso aparece na escolha das palavras 
"homem" (adulto) para os jogadores, enquanto as referências às jogadoras estão divididas entre as palavras "mulher" e "menina", a segunda infantilizadora. $\mathrm{O}$ uso dessas expressões por comentadoras mulheres converge com os resultados encontrados por Oliveira (2014) sobre o reforço involuntário de estereótipos de gênero por jogadoras.

A centralidade da palavra "homem", bem como das duas palavras utilizadas para fazer referência às jogadoras, reflete a realização do debate, que seria centrado na questão do gênero. Os termos da discussão aparecem mais claramente no núcleo verde, em palavras como "preconceito", "iguais", "direitos", que também estão mais fortemente associadas. Essa discussão está presente também no núcleo rosa, por exemplo "respeito", "iguais" e "machismo"; porém, neste grupo, os conceitos aparecem fracamente associados entre si, mostrando que outros assuntos dominam mais a conversa.

De modo geral, pode-se dizer que a discussão sobre gênero não aparece muito e, quando aparece, é problematizada pelos membros da comunidade.

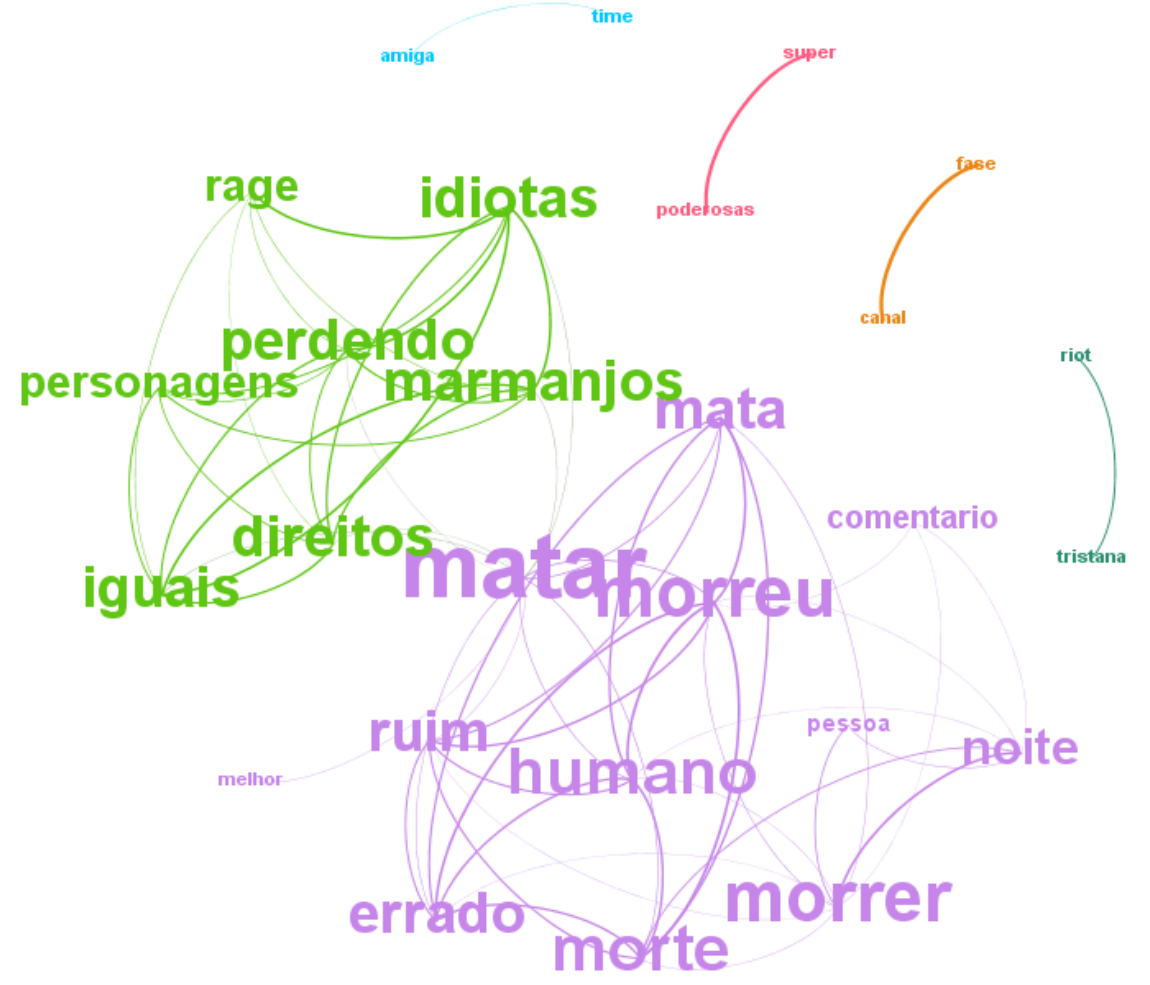

Figura 2: mapa normalizado dos posts e comentários que continham as palavras-chave mulher(es), menina (s), garota(s) e afins, na página League of Jungle, no ano de 2015. 
A Figura 2 traz os dados normalizados, mostrando os assuntos mais associados aos dados. Aqui vemos claramente uma discussão de gênero (grupo verde), elogios às mulheres (grupo vermelho) dentre outros assuntos. De modo geral, as jogadoras reclamam de serem "mortas" por serem mulheres ou pelo preconceito geral.

Deste modo, ainda que o mapeamento realizado não tenha apontado relevância quantitativa nos registros sobre discursos de violência e gênero, eles existem. Ou seja, isso não significa ausência de tais discursos na vivência de jogadores. Embora não contassem com publicações em grande quantidade e com regularidade significativa, a própria existência de diversas páginas e grupos dedicados à denúncia de casos de violência de gênero, como a "Gamer, você é machista"13 e a "Machistas no Mundo Geek"14, aponta para a importância desse tipo de ocorrência. No mapa normalizado,por exemplo, vemos que a reclamação existe, embora tenha menos destaque quantitativamente.

Dois cenários seriam compatíveis com a baixa quantidade e falta de regularidade de posts e comentários sobre violência de gênero: no primeiro, a baixa ocorrência seria devida ao fato de que esse tipo de incidente é raro entre os jogadores brasileiros; no segundo, os posts e comentários não são realmente raros, mas não são encontrados porque são apagados das páginas. No primeiro cenário, é possível que a violência de gênero ocorra, mas as jogadoras não se dêem conta dela. Embora não seja essa a conclusão de Fortim e Grando (2014) e de Oliveira (2014), a ideia é convergente com os dados apresentados em seus trabalhos. Pode estar ocorrendo também o silenciamento dos registros de violência de gênero, por opção das jogadoras, que prefeririam não publicar sobre as agressões testemunhadas ou sofridas.

No segundo cenário, os moderadores das páginas podem ter optado por excluir ou ocultar esses posts devido a ataques de trolls, que não são incomuns

${ }^{13}$ Disponível em: <https://www.facebook.com/gamermachista > Acesso em: 13 abr. 2017.

${ }^{14}$ Disponível em: <https://www.facebook.com/machistasdomundogeek/>. Acesso em: 13 abr. 2017. 
na internet brasileira (FRAGOSO, 2006, 2014, 2015), e que têm entre seus alvos prediletos grupos ou pessoas em posições fragilizadas, inclusive vítimas de violências anteriores (HERRING, 2003). Além disso, existe um histórico de atração de trollagens em games relativas a questões de gênero (DIBBEL, 1993; JOHNSTON, 2014). Se esse tipo de registro tende a tornar-se o epicentro de novas expressões de violência, apagar ou ocultar os posts e seus comentários seria uma forma de conter a escalada da violência de gênero nas próprias páginas e grupos criados para denunciá-los.

Diante dessas possibilidades, entende-se que as jogadoras brasileiras são alvo de violência de gênero, mas as evidências não podem ser encontradas, seja porque elas não se dão conta das agressões que sofrem, a exemplo do que notamos nos resultados de Fortim e Grando (2014), ou porque não registram os casos de agressão ou, ainda, porque seus registros acabam sendo ocultados. $\mathrm{Na}$ ausência desses rastros, torna-se impossível provar empiricamente a ocorrência e a importância da violência contra a mulher nos games. Para um olhar mais superficial, as evidências podem sugerir que essa violência não existe.

\section{Conclusão}

Neste trabalho, buscamos diagnosticar e discutir a violência simbólica contra as mulheres brasileiras em espaços online dedicados aos games. A literatura existente aponta a violência de gênero nos jogos e nos ambientes a eles relacionados, chamando atenção para fatores como a caracterização dos personagens femininos e tratamentos diferenciados conferidos a jogadoras mulheres, nos quais a agressão pode ser evidente e explícita (como chamar a jogadora de vadia) ou camuflada em protecionismos e atenções exageradas.

Para uma aproximação empírica, optamos por acompanhar 10 páginas e grupos do Facebook dedicadas a games, especialmente aquelas voltadas para denúncias de violência, violência de gênero e temas correlatos. Ao contrário do que era esperado, em um período de seis meses não foram encontrados posts sobre violência de gênero em quantidade ou com regularidade representativas nessas páginas. 
Uma abordagem mista, combinando métricas de análise de redes e análise de contingência, foi aplicada à página com maior número de posts e comentários ao longo de um ano. O tema emergiu em uma proporção bastante reduzida de registros, porém foi possível perceber diferenças na escolha de vocabulário para fazer referência a jogadores homens e a jogadoras mulheres, bem como à problematização das questões de gênero pela comunidade que interage na página analisada. Além disso, os dados também indicaram a ocorrência de agressões às jogadoras, especialmente nas reclamações de que seus avatares são mortos pelos jogadores homens.

A ausência de registros de violência de gênero em quantidade e com regularidade suficiente para caracterizar o fenômeno não significa que ele não aconteça. A própria existência de um bom número de páginas e grupos dedicados ao tema aponta em sentido contrário. Entre as possibilidades mais prováveis, destacamos: a) que as jogadoras podem não se dar conta das situações de violência de gênero, o que seria convergente com dados encontrados em trabalhos de outros autores; b) que as jogadoras percebam as agressões, mas prefiram não publicar sobre elas; c) que as publicações aconteçam, mas transformem-se facilmente em focos de novas manifestações de violência, o que levaria os moderadores das páginas ou grupos a apagarem as postagens. Em qualquer uma dessas hipóteses, a ausência de registros de violência de gênero entre jogadores brasileiros constitui não apenas um empecilho para os estudos sobre o tema, mas abre o caminho para sua negação em interpretações interessadas ou pouco cautelosas.

\section{Referências}

ALVES, L. Game over: jogos eletrônicos e violência. São Paulo: Siciliano, 2005 .

BARDIN, L. Análise de Conteúdo. Lisboa: Edições 70, 2004.

BOROSKI, M.; CARVALHO, F. C. de. A presidência tem gênero: o conteúdo relacionado a Dilma Rouseff nas capas de revista durante o segundo mandato. In: CONGRESSO INTERNACIONAL COMUNICAÇÃO E CONSUMO. São Paulo, outubro 2016.Anais...São Paulo: 2016.

BOURDIEU, P. Language and Symbolic Power. Trans. Gino Raymond and Matthew Adamson. Cambridge, MA: Harvard UniversityPress, 1991. 
DIBBELL, J. My Tiny Life: crime and passion in a virtual world. New York: Henry Holt and Company, 1998.

DILL, K. e THILL, K. Video game characters and the socialization of gender roles: young people's perceptions mirror sexist media depictions In: Sex Roles. v.57. pp. 851-864. DOI 10.1007/s11199-007-9278-1.

FELINTO, E. A Religião das Máquinas: Ensaios Sobre o Imaginário da Cibercultura. Porto Alegre: Sulina, 2005.

FISCHER, H. D. Sexy dangerous and ignored: an in-depth review of the representation of women in select video game magazines. In: Games and culture. v.10, n.6, 2015, p.551-570. Disponível em $<$ http://journals.sagepub.com/doi/abs/10.1177/1555412014566234>. Acesso em: 13 abr. 2017.

FRAGOSO, S. Towards a Semiotic Toy: designing an interactive audio-visual artefact for playful exercise of meaning construction. Tese de doutorado defendida no Institute of Communication Studies, The University of Leeds, 1998.

Conectibilidade e geografia em sites de rede social: um olhar sobre as relações entre território e identidade e a permeabilidade online/off-line a partir do Orkut. Revista Galáxia, São Paulo, n. 16, p. 109121, dez. 2008.

Cunctus ergo Sum: crítica à compreensão cartesiana de sujeito nos estudos da cibercultura. In. TRIVINHO, E.; REIS, A. P. (Orgs.) A cibercultura em transformação: poder, liberdade e sociabilidade em tempos de compartilhamento, nomadismo e mutação de direitos. São Paulo: ABCiber; Instituto Itaú Cultural, 2010. Disponível em $<$ http://abciber.com/publicacoes/livro2/textos/?autor=Suely Fragoso $>$ Acesso em 24 de abril de 2017

HUEHUEHUE BRBR: The Carnivalesque Griefing Behaviour of Brazilian Online Gamers. In: STRANO, Michele; HRACHOVEC, Herbert; FRAGOSO, Suely; ESS, Charles; VAN DER VELDEN, Maja. (Org.). CATaC 2014: Culture, Technology, Communication. 1ed.Oslo: University of Oslo, 2015, v. 1, p. 167-185.

FRAGOSO, S.; HACKNER, F. Huehuehue BR é só zueira: um estudo sobre o comportamento disruptivo dos brasileiros nos jogos online. Educação em um Mundo em Tensão: insurgências, transgressões, sujeições. Porto Alegre. 2017.

FREDA, S. Violência Discursiva: O poder simbólico na conversação sobre Dominação e Gênero nos sites de rede sociais. In: Anais do XXXIV Congresso Da Sociedade Brasileira De Computação. Brasília, DF. 28 a 31 de julho de 2014. Disponível online em <http://www.each.usp.br/digiampietri/BraSNAM/2014/p25.pdf> Acesso em 24 de abril de 2017 
FRIMAN, U. The Concept and research of gendered game culture. Proceedings of the 2015 DiGRA International Conference. v. 12. May. 2015.

FONSECA, L.L. GamerGirls: As mulheres nos jogos digitais sob a visão feminina. Dissertação de Mestrado apresentado ao Programa de PósGraduação em Ciências da Comunicação da Universidade do Vale dos Sinos. São Leopoldo. 2013. Disponível online em<http://search.ebscohost.com/login.aspx?direct=true\&db=cato1698a\& AN=unis.410403\&lang=pt-br\&site=eds-live\&authtype=uid $>$ Acesso em 24 de abril de 2017

FORTIM, I.; GRANDO, C. de M. Attention whore! Perception of female players who identify themselves as women in the communities of MMOs.

Proceedings of DiGRA 2013: DeFragging Game Studies. 2014.

HERRING, S. Gender and power in online communication. In: HOLMES, J.; MEYERHOFF, M.(Eds).The handbook of language and gender, Malden, Mass.: Blackwell, 2003. p. 202-228. Disponível em: < http://ella.slis.indiana.edu/ herring/gender.power.pdf>. Acesso em: 13 abr. 2017.

HOLLANDA, S. B. Raízes do Brasil. São Paulo: Cia das Letras. 1995.

IVORY, J. Still a man's game: gender representation in online reviews of video games. Mass Communication \& Society. November, 2006.

JOHNSTON, C. Chat logs show how 4chan users created \#GamerGate controversy. September, 2014. Disponível online em $<$ https://arstechnica.com/gaming/2014/og/new-chat-logs-show-how4chan-users-pushed-gamergate-into-the-national-spotlight/> Acesso em 24 de abril de 2017

LINS, B. A. 'Pornografia de vingança': pensando o trabalho de campo na e com a internet. In: Anais do 40 Encontro Da Associação Nacional De Pós-Graduação E Pesquisa Em Ciências Sociais, Caxambu-MG,de 24 a 28 de outubro, 2016. Disponível online em <http://www.anpocs.com/index.php/papers-40-encontro/spg-3/spgo83/10030-pornografia-de-vinganca-pensando-o-trabalho-de-campo-na-ecom-a-internet/file> Acessso em 24 de abril de 2017

MOTA, F. F.; BIROLO, F. Mídia, gênero e eleições: peças na produção de política como ela é. In: Anais do XXIII Encontro Anula da Compós. Universidade Federal do Pará, 27 a 30 de maio.2014. Disponível online em <http://compos.org.br/encontro2014/anais/> Acesso em 24 abril de 2017

OLEGÁRIO, M. da L. Lima, R. de A. e Borges, L. L. Games e violência numa perspectiva de gênero. Revista Debates em Educação. Vo. 1. 2009. Disponível online em<http://www.genderit.org/sites/default/upload/games_e VCM.pdf $>$ Acesso em 24 de abril de 2017

OLIVEIRA, R. O. Garotas que jogam videogame: expressões de identidade e interações sobre cultura gamer no Facebook. Dissertação de Mestrado 
apresentado ao Programa de Pós-Graduação em Ciências da Comunicação da Universidade do Vale dos Sinos.São Leopoldo. 2014. Disponível online em

$<$ http://search.ebscohost.com/login.aspx?direct=true\&db=cato1698a\&AN $=$ unis.417041\&lang=pt-br\&site=eds-live\&authtype=uid $>$ Acesso em 24 de abril de 2017

OSGOOD, C. The representational model and relevant research methods. In: POOL, I. de S. (Org.). Trends in Content Analysis, Urban, IL: Univ. of Illinois Press, 1959.

PROVENZO Jr, E. F. Video Kids: making sense of Nintendo. Cambridge, Massachusets: Harvard University Press,1991.

RECUERO, Raquel. Discutindo Análise de Conteúdo como Método: O Dia da Consciência Negra no Twitter. Cadernos de Estudos Linguísticos (UNICAMP), v. 56, p. 281-309, 2014. Disponível em: < http://revistas.iel.unicamp.br/index.php/cel/article/view/4334>. Acesso em: 17 abr. 2016

RECUERO, R.; BASTOS, M.; ZAGO, G. Análise de redes sociais para mídia social. Porto Alegre: Sulina, 2015.

RIBEIRO, M. et al. Games e violência: A brincadeira do mundo contemporâneo.In: Anais do X Simpósio Brasileiro De Games E Entretenimento Digital, Salvador, BA. 7 a 9 de novembro de 2011. Disponível online em $<$ http://www.sbgames.org/sbgames2011/proceedings/sbgames/papers/ga mesforchange/SBGames-GamesForChange-violencia.pdf $>$ Acesso em 24 de abril de 2017

SOARES, P. A propagação da violência online: análise de enunciados violentos emitidos à torcedora acusada de racismo contra goleiro Aranha. Verso e Reverso (Unisinos. Online), v. 30, p. 23-33, $2016 \mathrm{a}$.

SOARES, P. LINGUÍSTICA, LETRAS E ARTES. In: SOARES, Pricilla. (Org.). Humor e violência simbólica no Facebook: como os comentários humorísticos de uma postagem podem apresentar discursos violentos contra a mulher. Pelotas: Editora UFPel, v. 1, p. 93-109, $2016 \mathrm{~b}$.

STOCKER, P.C.; Dalmaso, S.C. Uma questão de gênero: ofensas de leitores à Dilma Rouseff no Facebook da Folha. In: Revista Estudos Feministas vol.24 no.3 Florianópolis Sept./Dec. 2016

WASSERMAN, S.; FAUST, K. Social Network Analysis. Cambridge: Cambridge University Press, 1994.

WERTHEIM, Margareth. The Pearly Gates of Cyberspace: a history of space from Dante to the Internet. New York, W. W. Norton \& Company, 1999.

YEE, N. "Maps of Digital Desires: Exploring the Topography of Gender and Play in Online Games." In KAFAI, Y.; HEETER, C.; DENNER, J.; SUN, J. (Orgs.) 
Beyond Barbie and Mortal Kombat: New Perspectives on Gender and Gaming, , p. 83-96. Cambridge, MA: MIT Press, 2008.

ŽIŽEK, S. Violence: Siz Sideways Reflections. London: Picador, 2008. 